\title{
The slings and arrows of communication on nanotechnology
}

\author{
Johannes Simons · René Zimmer • \\ Carl Vierboom · Ingo Härlen · \\ Rolf Hertel · Gaby-Fleur Böl
}

Received: 26 September 2008/ Accepted: 4 May 2009/Published online: 20 May 2009

(C) Springer Science+Business Media B.V. 2009

\begin{abstract}
According to numerous surveys the perceived risk of nanotechnology is low and most people feel that the benefits outweigh the risks. This article provides greater insight into risk perception and concludes that the positive attitude to nanotechnology is based not on knowledge but on hope and fascination. The perceived risk is low because of a lack of vivid and frightening images of possible hazards. If news flashes were to link nanotechnology to concrete hazards or actual harm to people, attitudes might suddenly change. Risk communication faces the problem of dealing with a public at large that has little or no knowledge about the technology. As it takes time and extensive additional research to develop appropriate communication strategies and disseminate them to the relevant institutions, this exercise should be started immediately.
\end{abstract}

Keywords Nanotechnology $\cdot$ Risk perception · Risk communication · Technology acceptance

J. Simons $(\bowtie)$

Institute for Food and Resource Economics,

University Bonn, Nußallee 21, 53115 Bonn, Germany

e-mail: johannes.simons@ilr.uni-bonn.de

R. Zimmer · R. Hertel · G.-F. Böl

Federal Institute for Risk Assessment, Thielallee 88-92, 14195 Berlin, Germany

C. Vierboom · I. Härlen

Vierboom \& Härlen Wirtschaftspsychologen,

Krefelder Str. 36, 50670 Colongne, Germany

\section{Introduction}

Despite the enormous potential of nanotechnology to develop and improve products and production processes, various surveys confirm that it is an unknown element for most of the population. Nevertheless, an overwhelming proportion of respondents can be prompted to estimate the risk-benefit ratio. Furthermore, the majority is of the opinion that the benefits outweigh the risks (Cobb and Macoubrie 2004; Elkins 2005; Hart Research Associates (HRA) 2006, 2007, 2008; Rosenbladt and Schwupp 2007; Kahan et al. 2007; Market Attitude Research Service (MARS) 2008). Depending on the field of application, the results of the studies analysing consumer acceptance of nanotechnology may vary. In the opinion of the majority of the surveyed groups, food should be free from nanotechnology (Elkins 2005; TA-Swiss 2006; Fleischer and Quendt 2007; Zimmer et al. 2007; HRA 2007; MARS 2008).

The results of the surveys back the hypothesis that nanotechnology is a technology which is indeed widely accepted but not when it is linked to food, and that the attitude to nanotechnology is driven by determinants other than knowledge. Given the lack of knowledge and the growing distribution of products based on nanotechnology, public attitudes may suddenly change when news of risks is disseminated. Nanotechnology may no longer be perceived as a friendly technology but as an allembracing threat. 
If news were to be broadcast about the risks of nanotechnology, communication faces the challenge of explaining this technology to a poorly informed public at large. In order to communicate adequately and in a targeted manner about nanotechnology in a given situation, it is necessary to understand public perceptions.

Against this backdrop, this article addresses the problems of risk communication on nanotechnology. In addition to a literature analysis, it draws on a qualitative study and a standardised questionnaire used in Germany in a project of the Federal Institute for Risk Assessment (BfR). The results are documented in a comprehensive report (Vierboom et al. 2009). Starting with the results of the BfR project, this article (1) presents the results of a research project that analyses the recognition, risk perception and acceptance of nanotechnology in Germany and compares them with findings of other surveys conducted in Germany, the United States and Australia; (2) outlines the consequences for the steadfastness of public opinion; (3) draws conclusions for risk communication on nanotechnology.

\section{Approach}

The BfR project focussed on the following questions about nanotechnology:

- How widespread is information?

- Does acceptance depend on the application area?

- How is the risk-benefit ratio perceived?

- Which information channels are important for the dissemination of knowledge?

- How important is this technology considered to be for the location Germany?

- What quantitative importance do the various forms of handling information have?

In the BfR project, qualitative and quantitative researches were linked. This approach provides greater insight into the determinants of risk perception and the risk communication framework in Germany.

Qualitative research was conducted as an explorative analysis. It is based on morphological psychology, an approach developed from Freud's depth psychology and Gestalt psychology. This approach focusses on how people experience products, events and information and how they integrate them into their everyday lives (Schulte 2005; Fitzek and Salber 1996). When it comes to handling the subject of nanotechnology and information about it, this approach helps to ascertain how people (mentally) accept this technological development and reveals the schemata they use to evaluate it.

For the qualitative part of the project, a total of 50 in-depth interviews were conducted: 30 one-on-one interviews and two group discussions with 10 participants each. Participants were selected in line with the requirement to cover a broad range of ways of dealing with nanotechnology and information about it.

Given the selection procedure and the small sample size, no quantitative results can be presented. This is why the qualitative study was supplemented by a later standardised survey that was based on the qualitative results regarding the poor knowledge of consumers about nanotechnology and the way they perceive and process information about it. The questionnaire was tested for comprehensibility and clearness.

The population in the standardised questionnaire $(n=1,000)$ were people aged between 16 and 60, accessible by phone (registered in public telephone books that include cell phones), who were capable of understanding and answering questions in German. Based on this population, a representative sample in terms of sex, age and federal state was established. The interviews were carried out as telephone interviews during September and October 2007.

The survey concept bears in mind the limited level of knowledge about nanotechnology. In the course of the interview, a short description of the term nanotechnology was given at an appropriate point. Furthermore, the wording of a set of questions addressing the acceptance of products manufactured using nanotechnology pointed out the special product characteristics and their relevance for daily life (e.g. encapsulate vitamins in order to improve their impact in the body). Against the backdrop of the qualitative results, this is a suitable procedure as the perception of nanotechnology is driven by product characteristics and not by knowledge about how nanotechnology works. Hence, information was provided directly and indirectly during the interview in a way that mirrors how consumers deal with nanotechnology. The procedure made it possible to include information in the interview and to activate any existing knowledge despite the limited time available. 
In this article, we concentrate on the results on the dissemination of information, the perception of nanotechnology, the risks and some results on information channels. These are the core areas when it comes to understanding the difficulties of communication on nanotechnology.

\section{Comparable studies}

The results described below are primarily based on the research conducted within the German study initiated by the BfR (Vierboom et al. 2009). In addition, we present findings from comparable standardised surveys conducted in Germany, Australia and the United States in order to

(1) place the German results in an international context and

(2) assess whether the interpretation of the results and the conclusions for risk communication can be transferred to the other surveyed countries, too.

Nanotechnology surveys in Germany

There are two additional representative studies on nanotechnology in Germany. The first was conducted in September 2004 by the consultancy agency Komm Passion (2004). The field study was done by face-toface interviews using a standardised questionnaire and included 1,019 German householders over the age of 14 . The second German survey on nanotechnology was conducted by the Deutsches Institut für Wirtschaftsforschung (German Institute for Economic Research) in Berlin in 2006 (Rosenbladt and Schwupp 2007). The survey addressed the perception and assessment of new developments in science and technology, with nanotechnology serving as a current and concrete example. A total of 1,063 people were included in the survey. The three German surveys were not recurrent surveys but some questions were similar. Hence, the studies are only comparable to a limited degree.
Nanotechnology surveys in Australia

In Australia, the company Market Attitude Research Services (MARS) was commissioned by the Innovation Division of the Department of Industry, Tourism and Resources (an Australian government agency) to undertake national telephone survey within the Australian community to measure awareness and understanding of nanotechnology. The first survey in June 2005 was conducted as a baseline for measuring changes in awareness and attitudes towards nanotechnology in the following years. This survey included 1,000 people over the age of 18. In March and April 2007, the second telephone survey of 1,000 randomly selected households from metropolitan, regional and rural Australia was undertaken to gauge community understanding of nanotechnology. And the third national random telephone survey of 1,100 people over the age of 18 was conducted in May 2008. The surveys were recurrent and are available as short reports (MARS 2005, 2007, 2008). Elkins (2005) undertook a more detailed analysis of the 2005 survey results.

Nanotechnology surveys in the United States of America

In the United States, there are three recurrent nationwide surveys on nanotechnology conducted by HRA (2006, 2007, 2008). The first telephone survey among 1,014 adults about awareness of and attitudes towards nanotechnology took place in August 2006. The second survey was conducted in August 2007 among 1,014 adults. And the third survey from August 2008 included 1,003 adults. In addition to these three HRA surveys, another nationwide survey was conducted in December 2006 by the Cultural Cognition Project at Yale Law School (Kahan et al. 2007). The sample consisted of approximately 1,850 Americans and collected information on relevant individual characteristics and attitudes towards nanotechnology risks. In addition, the role of information in the perception of nanotechnology was tested. The first national survey of public attitudes towards nanotechnology in the United States was a random-digit dialled survey of 
1,536 adults 18 years or older (Cobb and Macoubrie 2004). The survey was conducted between late March and early April 2004.

\section{Results}

Recognition of and information about nanotechnology

As for Germany, recognition of the word nanotechnology was addressed in each of the three abovementioned surveys by means of an open-ended question. Based on the available data and results, the answers can be grouped in the categories word unknown, word known but without specification and word known with specification.

A comparison of the three surveys conducted between 2004 and 2007 reveals that recognition of the word nanotechnology has considerably increased (Table 1). In a 2004 survey (Komm.Passion 2004), $15 \%$ of the respondents indicated that they had already heard of the term and could give some specification. In the 2007 BfR survey (Vierboom et al. 2009), this figure amounts to $52 \%$. Consumers are now more familiar with the term nanotechnology. Nevertheless, roughly one third of the German population is not familiar with the word and a further $15 \%$ is unable to specify it.

A closer look at the specifications of nanotechnology reveals what respondents associate with the word. The 2007 survey results are summarised in Fig. 1. They point out that the word is mainly linked to miniaturisation and to self-cleaning products. Hence, people automatically think of products and their benefits when they think of nanotechnology. They have scarcely any idea about how it works and do not link nanotechnology to vivid images of possible harm.

The previous studies in 2004 and 2006 produced similar results:

- In the 2004 survey, about 55\% of the answers referred to miniaturisation, $30 \%$ to products and the benefits offered by nanotechnology in these products, and only $15 \%$ referred to science or to future technology. ${ }^{1}$

\footnotetext{
${ }^{1}$ The results published refer to the share of respondents with answers in the respective categories. In order to make the
}

- Concerning the results of the 2006 questionnaire, the answers were classified according to the categories profound knowledge (about $40 \%$ of those who specified nanotechnology) and vague knowledge (about $60 \%$ of those who specified nanotechnology). The subcategories do not match the categories in the two other surveys, but one subcategory comprises small particles, physics, microtechnology which seems to be similar to miniaturisation. This subcategory covers about $50 \%$ of the answers.

The answers to the open-ended question are in line with the results of the qualitative study. Even if the interviewer insisted, scarcely anyone was able to give a comprehensive idea of the principles of nanotechnology, either right or wrong. As a rule, interviewees were surprised about their limited ability to understand nanotechnology. Their knowledge about engineering and natural sciences was not sufficient to shape the ideas and concepts that help to explain these benefits. However, even though they were not familiar with the technology behind the products, they were not scared. In contrast, grasping their own boundaries can foster interest in and fascination with nanotechnology.

Nanotechnology and miniaturisation are closely linked. People can experience them in their everyday lives, e.g. in cell phones, laptops. They understand that technical devices are becoming smaller, more powerful and combine different features.

The self-cleaning effect is supposed to be an intelligent and sound copy of nature. This impression is enforced by the name lotus effect which reminds people in Germany of nature and of accepted Asian religions. Recognising that respective products are available on the market, being aware of their obvious benefits in the normal course of life and the fact that nanotechnology tends to be perceived as a sound technology tends to make people more kindly disposed towards it.

Neither in the qualitative nor in the open-ended question in the standardised survey did terrifying images play an important role. The same is true for the 2004 and 2006 questionnaires. Just one of the

Footnote 1 continued results comparable with those of the other surveys, we rebased them on the number of answers. 
Table 1 Recognition of the word nanotechnology in different surveys in Germany

\begin{tabular}{llll}
\hline & $\begin{array}{l}09 / 2004(\text { Komm. } \\
\text { Passion 2004) }\end{array}$ & $\begin{array}{l}\text { 07/2006 (Rosenbladt } \\
\text { and Schwupp 2007) }\end{array}$ & $\begin{array}{l}\text { 10/2007 (Vierboom } \\
\text { et al. 2009) }\end{array}$ \\
\hline Word unknown (\%) & 48 & 48 & 33 \\
Word known but without specification (\%) & 30 & 16 & 15 \\
Word known with specification (\%) & 15 & 36 & 52 \\
\hline
\end{tabular}

a The deviations from $100 \%$ are given in the original publication

b Rosenbladt and Schwupp (2007) merged the categories Word unknown and Word known but without specification, while the survey data were collected separately. The specific percentages for both categories were kindly provided by Schupp (Deutsches Institut für Wirtschaftsforschung, Berlin)

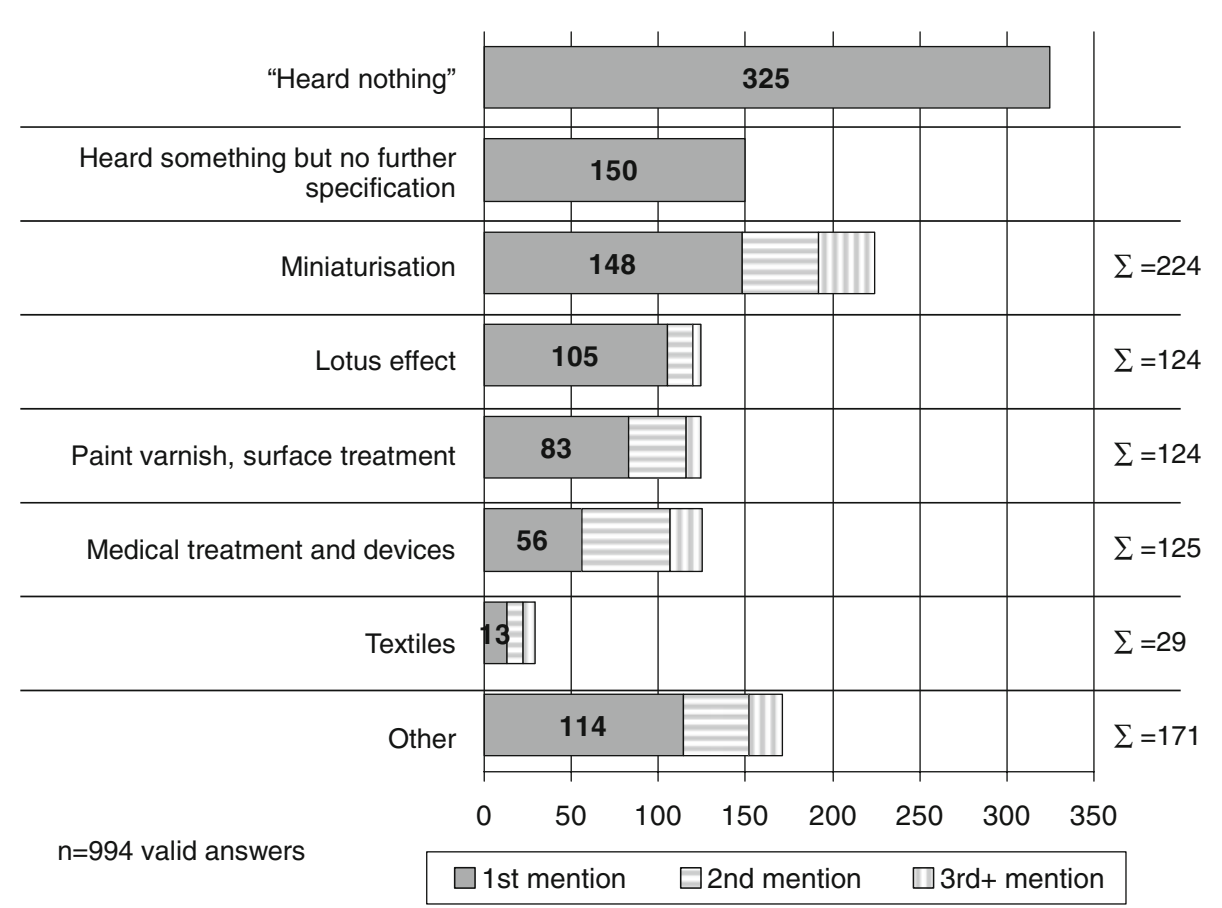

Fig. 1 Spontaneous connotations elicited by the word nanotechnology

answers is assigned to the category risk, hazard. Obviously the word nanotechnology is not spontaneously associated with frightening ideas. Spontaneously perceived concerns are not driven by knowledge about the technology but rather by vague and general ideas about possible risks.

In summary, many people know products based on nanotechnology or can imagine their benefits. This leads to a fascination that is not based on knowledge about the principles of the underlying technology.

The recurring surveys described above in Australia (MARS 2005, 2007, 2008; Elkins 2005) produced similar results (Table 2):
- The share of people stating that they had not heard the term nanotechnology fell from $49 \%$ in 2005 to $34 \%$ in 2008.

- The share of people agreeing to: Know what nanotechnology means but don't know how it works increased from $19 \%$ to $29 \%$.

- Only a small percentage claimed to know in detail what nanotechnology means and how it works (4\% in 2005 and $8 \%$ in 2008)

The US surveys do not focus explicitly on recognition of the term nanotechnology but ask about the amount of perceived information. Even though 
Table 2 Recognition of the word nanotechnology in different surveys in Australia

\begin{tabular}{llll}
\hline & $\begin{array}{l}\text { 06/2005 (MARS 2005; } \\
\text { Elkins 2005) }\end{array}$ & $\begin{array}{l}\text { 04/2007 } \\
\text { (MARS 2007) }\end{array}$ & $\begin{array}{l}\text { 05/2008 } \\
\text { (MARS 2008) }\end{array}$ \\
\hline $\begin{array}{l}\text { Word unknown (\%) } \\
\begin{array}{l}\text { Word known but without } \\
\quad \text { specification (\%) }\end{array}\end{array}$ & 49 & 37 & 34 \\
$\begin{array}{l}\text { Word known with specification (\%) } \\
\text { (M) }\end{array}$ & 23 & 34 & 29 \\
\hline
\end{tabular}

Table 3 Amount of perceived information about nanotechnology in different surveys

\begin{tabular}{llllll}
\hline & $\begin{array}{l}\text { USA 04/2004 } \\
(\text { Cobb and Macoubrie 2004) }\end{array}$ & $\begin{array}{l}\text { USA 08/2006 } \\
\text { (HRA 2006) }\end{array}$ & $\begin{array}{l}\text { USA 12/2006 } \\
\text { (Kahan et al. 2007) }\end{array}$ & $\begin{array}{l}\text { USA 08/2007 } \\
\text { (HRA 2008) }\end{array}$ & $\begin{array}{l}\text { Germany 10/2007 } \\
\text { (Vierboom et al. 2009) }\end{array}$ \\
\hline A lot (\%) & 4 & 10 & 5 & 7 & 9 \\
Some/Just a little (\%) & 45 & 47 & 42 & 43 & 68 \\
Nothing at all (\%) & 52 & 42 & 53 & 49 & 23 \\
\hline
\end{tabular}

$\bar{a}$ Cobb and Macoubrie (2004) merged the categories a lot and some, whereas the survey data were collected separately. The specific percentages for both categories were kindly provided by M. Cobb (NC State University)

the wording of the questions is different, the results (Table 3) reveal that about half of Americans have never heard of nanotechnology and less than 10\% indicate that they have heard a lot. When comparing the results over time, the level of information did not increase in the United States.

In contrast to the US surveys, the German 2007 questionnaire (Vierboom et al. 2009) addressed the subject of perceived information after giving a short explanation about nanotechnology: Nanotechnology makes it possible to generate particles as small as atoms or molecules. Materials made of these particles have special physical, chemical or biological characteristics. The subsequent question about the amount of information led to the following results: $23 \%$ stated that they had heard nothing at all, $68 \%$ some and $9 \%$ a lot. When comparing the results with those presented in Table 1 , it becomes obvious that the short information about nanotechnology had an impact. Before a short introduction to nanotechnology was given, about one third of the respondents stated that they did not know what the word meant. After the introduction, this share decreased to about one quarter. Obviously, the additional information helps to place the word nanotechnology in a broader context. This leads to greater awareness. That is why the results for Germany are not directly comparable with the results for the United States.
In summary, the results reveal a low level of recognition and information. This is true not only for Germany but for Australia and the United States as well.

\section{Emotions}

Although respondents in the BfR project did not know very much about nanotechnology, they were willing to reveal their overall feelings about this technology and gave their personal estimation of the risk-benefit ratio. On the question How do you feel about nanotechnology?, 77\% answered that they felt good or very good (Table 4).

The results of the quantitative BfR survey correspond to the outcome of the in-depth interviews. In these interviews, hope for a new, sound technology played an important role, and there was little evidence of scepticism. Good feelings are based on the diffuse hope that nanotechnology might be a new, intelligent and environmentally sound approach to dealing with and solving urgent problems of humanity. Against this backdrop, there was a tendency to push aside uncomfortable feelings and to hold on to that diffuse hope (Vierboom et al. 2009). Many people trust in nanotechnology without being able to explain why.

Emotions were touched on in several studies but addressed with different questions (Table 4). The 


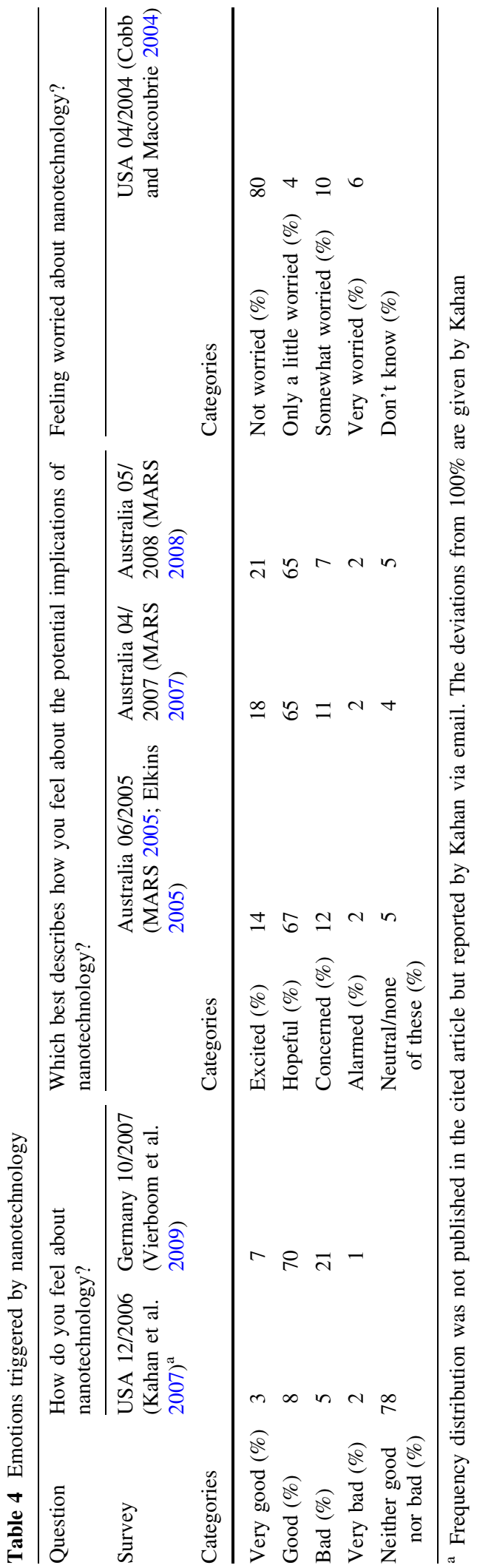

results provide some evidence that the categories offered to the respondents have a major impact on the outcome. In the 2006 survey in the United States (Kahan et al. 2007), there were five possible categories to answer the question How do you feel about nanotechnology?. In contrast, there were just four to answer the same question in the BfR project (Vierboom et al. 2009). Obviously, people tend to retreat to a neutral position if they are not prompted to decide. This may reflect limited knowledge of the subject. However, if they are encouraged to opt for one side, it seems that they tend to feel good about nanotechnology.

After summarising the results, the overall impression is that the vast majority of the population is not frightened of nanotechnology. The feelings triggered by nanotechnology are mainly ones of excitement and hope. A comparison of the results of the 2005 and 2008 surveys in Australia reveals that the positive feelings have increased slightly. The share of people feeling either excited or hopeful rose and the share of people feeling concerned or alarmed each decreased by $5 \%$ points (MARS 2005, 2007, 2008; Elkins 2005).

Hope is concentrated on medical treatment and on improved technologies for the environment (Table 5). Although people do not know very much about the technology, they hope it will provide solutions for the urgent problems facing humanity.

The outcomes of the surveys support the hypothesis again that there is considerable fascination and little perceived risk. Nanotechnology makes people feel hopeful about substantial improvements in different areas of application. Hope is concentrated on medicine and environmental technology.

\section{Perceived risk-benefit ratio}

Negative associations with a technology and positive effects can strongly influence its assessment (Alhakami and Slovic 1994). With respect to nanotechnology, Kahan et al. (2007) demonstrate the relevance of overall feelings about the technology for the evaluation of the risk-benefit ratio.

According to the BfR survey, about two-thirds of the German adult population feel that the benefits of nanotechnology will outweigh the risks, and one third estimates the risks as being greater than the benefits. In order to classify the results and compare them with the results of other surveys, it must be borne in mind 
Table 5 Most important potential benefit of nanotechnology

\begin{tabular}{llll}
\hline & $\begin{array}{l}\text { USA 04/2004 } \\
(\text { Cobb and } \\
\text { Macoubrie 2004) }\end{array}$ & $\begin{array}{l}\text { Australia 05/2008 } \\
(\text { MARS 2008) }\end{array}$ & $\begin{array}{l}\text { Germany 10/2007 } \\
(\text { Vierboom et al. 2009) }\end{array}$ \\
\hline Improved medical treatments (\%) & 57 & 79 & 41 \\
Improved environmental technologies (\%) & 16 & 12 & 25 \\
Improved security and defence capabilities (\%) & 12 & 5 & 18 \\
Improved consumer products (\%) & 4 & 3 & 12 \\
Improved food (\%) & & 4 & 4 \\
\hline
\end{tabular}

${ }^{a}$ Physical and mental improvements for humans was another category in the study

b The deviations from $100 \%$ are as given in the original publication

that the results referring to the estimation of risks and benefits of nanotechnology are influenced by the design of the questionnaire.

- According to HRA results (2008), the estimation of the risks and benefits of nanotechnology differs depending on whether the interviewees are provided with information on nanotechnology or not (Table 6). The information provided referred to risks and benefits as well and it helped people to decide in favour or against nanotechnology.

- If the option of an undecided answer is explicitly offered, many of the interviewees chose that option (Table 7).

However, independently of the specific wording of the questions, the questionnaire design, the amount and kind of presented information and the categories for the answers, more people suppose that benefits outweigh risks than vice versa. The benefit-risk coefficients given in Table 7 are higher than one in all the surveys except for the United States one in 2006. Nevertheless, it varies considerably between countries and different surveys but does seem to increase over time.

Table 6 Influence of providing information on risk-benefit estimation of nanotechnology

\begin{tabular}{lll}
\hline & $\begin{array}{l}\text { Initial impression of } \\
\text { risks and benefits of } \\
\text { nanotechnology }(\%)\end{array}$ & $\begin{array}{l}\text { Informed impression } \\
\text { of risks and benefits } \\
\text { of nanotechnology }(\%)\end{array}$ \\
\hline Benefit $>$ Risk & 20 & 30 \\
Benefit $=$ Risk & 25 & 38 \\
Risk $>$ Benefit & 7 & 23 \\
Not sure, & 48 & 9 \\
$\quad$ undecided & & \\
\hline
\end{tabular}

Source: HRA (2008)
Characterising risk perception

Even though there is hardly any awareness of concrete risks of nanotechnology, fears can easily be fuelled. This is especially true for unbound particles. In-depth interviews in the $\mathrm{BfR}$ project showed that people can find parallels to other risks that are commonly known such as particulate matter or asbestos. In this case, vague ideas of possible risks are replaced by pictures that cause uncomfortable feelings and fears.

The role of emotions for risk assessment by lay persons is common knowledge in the literature on risk perception. According to the psychometric paradigm (Slovic et al. 2000), risk perception is primarily driven by two factors: (1) dread risk that addresses a lack of controllability and perceived catastrophic potential and (2) unknown risk referring to the extent that a hazard is unobservable, unknown to those exposed, new, unknown to science and with delayed effects.

The perception of catastrophic potential is influenced by the vividness with which possible outcomes are presented mentally (Damasio 1994). Warnings have a greater effect if they are imbedded in anecdotes and connected to people who have been harmed as this enforces emotional involvement (Henddickx et al. 1989).

The specifics of the risk perception of nanotechnology help to explain the high level of acceptance but they also reveal that acceptance can turn into the opposite. On the one hand, empirical studies reveal that there is hardly any vivid imagery specifically associated with nanotechnology. Anecdotes about people who have suffered harm do not spring to mind spontaneously. Correspondingly, the perceived 
Table 7 Risk benefit estimation of nanotechnology in different surveys

\begin{tabular}{|c|c|c|c|c|c|c|c|}
\hline & \multicolumn{3}{|l|}{ Australia } & \multicolumn{3}{|l|}{ USA } & \multirow{2}{*}{$\begin{array}{l}\text { Germany } \\
10 / 2007 \\
\text { (Vierboom } \\
\text { et al. 2009) }\end{array}$} \\
\hline & $\begin{array}{l}\text { 06/2005 (MARS } \\
\text { 2005; Elkins } \\
\text { 2005) }\end{array}$ & $\begin{array}{l}\text { 04/2007 } \\
\text { (MARS } \\
2007)\end{array}$ & $\begin{array}{l}\text { 05/2008 } \\
\text { (MARS } \\
2008)\end{array}$ & $\begin{array}{l}\text { 08/2006 } \\
\text { (HRA } \\
2006)\end{array}$ & $\begin{array}{l}\text { 12/2006 } \\
\text { (Kahan et al. } \\
2007 \text { ) }\end{array}$ & $\begin{array}{l}\text { 08/2008 } \\
\text { (HRA } \\
2008)\end{array}$ & \\
\hline Benefit $>$ Risk $(\%)$ & 39 & 52 & 53 & 26 & 53 & 30 & 67 \\
\hline Benefit $=$ Risk $(\%)$ & 35 & 28 & 18 & 18 & & 38 & \\
\hline Risk > Benefit $(\%)$ & 8 & 5 & 3 & 49 & 36 & 23 & 33 \\
\hline Not sure, undecided (\%) & 18 & 15 & 26 & 7 & 11 & 9 & \\
\hline Benefit-risk coefficient & 4.9 & 10.4 & 17.7 & 0.5 & 1.5 & 1.3 & 2.0 \\
\hline
\end{tabular}

In some surveys the categories the risks of nanotechnology will greatly outweigh its benefits and the risks of nanotechnology will slightly outweigh its benefits as well as the categories the benefits of nanotechnology will slightly outweigh its risks and the benefits of nanotechnology will greatly outweigh its risks were summarised for better comparability

catastrophic potential is low. The connection between nanotechnology and miniaturisation as well as the idea that it copies nature in an intelligent way reduces perceived risks. However, fears can easily arise particularly if this technology is linked with unbound particles. Vivid imageries can be activated by drawing parallels from respirable dust or asbestos. In this case, catastrophic potential (cancer) is high, hazardcausing agents are not apparent and possible effects are delayed. Against the backdrop of research on risk perception and taking into account the characteristics of risk perception of nanotechnology, the high degree of acceptance cannot be regarded as enduring. Similar to the results of the BfR project, the surveys in Australia only identified the following vague ideas about perceived risks as well.

- In response to an open-ended question about the concerns regarding nanotechnology (Elkins 2005), the following answers were given: fear of unknown (20\%), may be misused by the wrong people (19\%), possible side-effects $(11 \%)$. No concerns were mentioned by $17 \%$. The rest of the answers referred to categories with low frequencies.

- In the 2008 survey respondents were prompted to comment on what they know about nanotechnology. Eighty two percent made no comment ${ }^{2}$ and $17 \%$ a positive one. Just $1 \%$ classified nanotechnology as a scary or worrying concept.

\footnotetext{
${ }^{2}$ Seventy-nine percent of the respondents made no comment whereas $3 \%$ stated that they did not know very much about nanotechnology or that it sounded too futuristic.
}

Nevertheless, the lack of ideas about risks connected with nanotechnology does not mean that people see it as a risk-free technology. More than $90 \%$ of the respondents in Germany agreed with the statement We should develop nanotechnology but keep an eye on the potential risks (Vierboom et al. 2009). In Australia, about two-thirds of the interviewees agreed with the statement that they are concerned about the unknown risks involved in the use of nanotechnology (MARS 2008). These results may be taken as indicators that public perception of nanotechnology risks can change because people could imagine there is a risk.

\section{Comparison to other risks}

In the standardised BfR questionnaire, the comparison of risks was not addressed mainly for the following two reasons: (1) time constraints and (2) information available from other surveys and indepth interviews. The results of the surveys show that nanotechnology is perceived as far less risky than other technologies:

- Elkins (2005) asked respondents to indicate the most worrying area of science and technology. Cloning (39\%), GM Food (38\%) and Stem Cell Research $(15 \%)$ were the areas mentioned most whereas nanotechnology only accounted for $4 \%$.

- In the 2008 survey (MARS 2008), people were asked whether or not they were excited, hopeful, concerned or alarmed about stem cell research, GM food and cloning. Out of these, $86 \%$ felt hopeful or excited and $9 \%$ alarmed or concerned 
about stem cell research. This is nearly equal to the assessment of nanotechnology (Table 4). In contrast, GM food (cloning) makes 25\% (30\%) feel excited or hopeful and 64\% (58\%) concerned or alarmed.

- In a previous study in Germany (Komm.Passion 2004), the share of the people who saw nanotechnology as risky was low (10\%) compared to genetic engineering (39\%) and atomic power $(47 \%)$.

- In the Eurobarometer 64.3 survey conducted in 2005, Gaskell et al. (2006) compared the assessment of different technology on the basis of an index. ${ }^{3}$ In the European population, nanotechnology has a similarly good score (0.60) to computer and information technology (0.76), wind energy (0.79) and solar energy (0.76). In contrast, nuclear energy scored negative $(-0.06)$. The ratio of optimists to pessimists is eight to one when it comes to nanotechnology.

The in-depth interviews revealed important differences regarding nanotechnology on the one hand, and radiation, atomic power and genetic engineering on the other. Nanomaterials are perceived as tangible and material contrary to radiation. In contrast to genetic engineering, nanotechnology does not interfere with the blueprint of life. In addition, the prospects of miniaturisation and of the self-cleaning effect are clear to many consumers. In contrast, there is a feeling that global enterprises misuse genetic engineering for their own economic gain. ${ }^{4}$

The role of socio-demographics

Looking at the determinants of risk perception, we find that socio-demographic factors are merely poor predictors. Results of multiple linear regression analysis (using the ordinary least squares method) with the risk-benefit ratio and overall feelings about

\footnotetext{
${ }^{3}$ In the Index of optimism they subtract the percentage of pessimists from the percentage of optimists and divide this by the combined percentage of optimists, pessimists and those who felt that this technology would have no impact. 'Don't know' responses were excluded.

${ }^{4}$ On the relevance of the involved enterprises for risk perception, compare Schütz and Wiedemann (2008). For the social context, compare Wiedemann and Schütz (2001).
}

nanotechnology as the dependent variables (Table 8) show that gender and education are significant independent variables whereas age and income are not. Hence, the low values of the $R$-squared indicate that only a very low share of the overall variance is explained by socio-demographic factors.

Taking the results from other studies into account, gender and education seem to be the most important socio-demographic determinants for risk assessment (HRA 2006, 2007; Kahan et al. 2007). Men are significantly more likely than women to think that benefits outweigh risks. And individuals who have greater knowledge of nanotechnology are far more likely to say that the benefits will outweigh the risks, and those who have no knowledge of the technology are more likely to say that the risks will outweigh the benefits.

Acceptance of nanotechnology in different application areas

The overall positive perception of nanotechnology does not hold for all areas of application. Even though there is hardly any concrete knowledge about risks, there are different degrees of rejection depending on the application area. The BfR questionnaire addressed the acceptance of nanotechnology in different consumer products and the willingness to buy them. The results provide evidence that people use typical schemata to evaluate products and to decide whether to buy them or not (Figs. 2, 3). Acceptance depends primarily on the areas of application. Differences exist in relation to the distance between the nano products and the human body. The closer the nano products come to the body, the lower the level of acceptance. If products based on nanotechnology enter the body, then acceptance falls markedly.

The differentiated acceptance of nanotechnology does not contradict positive feelings or a low level of perceived risk. As shown in Fig. 1, there are just a few products and the concept of miniaturisation, which are associated with the term nanotechnology. Food and cosmetics scarcely play any role for respondents. This leads to the conclusion that general questions about acceptance, evaluation and risk perception do not cover all areas of application. Against this backdrop, Figs. 2 and 3 supplement and differentiate the results regarding risk perception. 
Table 8 Results from a multiple linear regression (OLS) estimating the influence of socio-demographic variables on the risk-benefit ratio and an overall feeling about nanotechnology

\begin{tabular}{|c|c|c|c|c|}
\hline & \multicolumn{2}{|c|}{ Dependent variable: risk-benefit assessment } & \multicolumn{2}{|c|}{ Dependent variable: overall feeling about nanotechnology } \\
\hline & & $p$-value & & $p$-value \\
\hline Constant & 2.285 & 0.000 & 2.134 & 0.000 \\
\hline Gender $^{\mathrm{b}}$ & 0.332 & 0.000 & 0.231 & 0.000 \\
\hline Education & -0.104 & 0.000 & -0.042 & 0.018 \\
\hline Age & -0.002 & 0.311 & 0.001 & 0.349 \\
\hline Income & 0.037 & 0.105 & -0.015 & 0.299 \\
\hline Adjusted $R^{2}$ & 0.053 & 0.000 & 0.050 & 0.000 \\
\hline
\end{tabular}

a Coding of the dependent variable: Higher values indicate a higher relevance of benefits compared to risk

b Coding: male $=0$, female $=1$

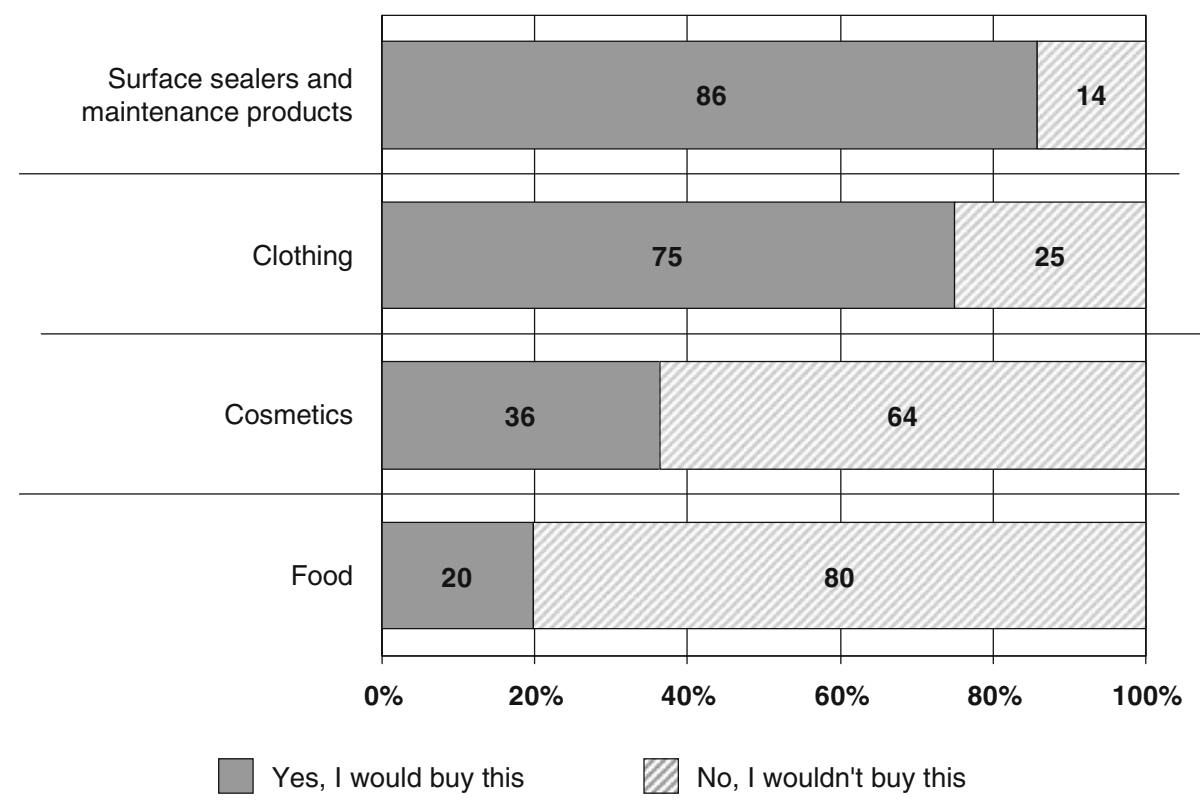

Fig. 2 Willingness to buy nano products dependent on product groups. Source: Vierboom et al. (2009)

Figure 3 illustrates that the overall acceptance of nanotechnology does not hold for all areas of application. Despite of the lack of knowledge, diffuse but uncomfortable emotions are aroused if the products come closer to the body.

The relevance of the subject to which nanotechnology is linked becomes obvious when examining the different levels of acceptance of nanotechnology in food and medical products. The hopes relating to nanotechnology are focussed on medicine (Table 5), and even though we did not ask about acceptance of nanotechnology in this area, we conclude from the ascertained hopes and from in-depth interviews that it is high. The typical expectation context of nanotechnology is healing and, therefore, it is viewed positively. Contrary to the positive perception of nanotechnology in conjunction with healing, it is seen negatively when linked to food. Obviously, people use additional criteria to decide whether they do or do not accept nanotechnology. In the context of food, nanotechnology is not natural, and hence, it goes against the common belief that natural is good and unnatural is bad. Again in the medical context, it is accepted that nanotechnology acts within the body, although in the context of food it is not. 


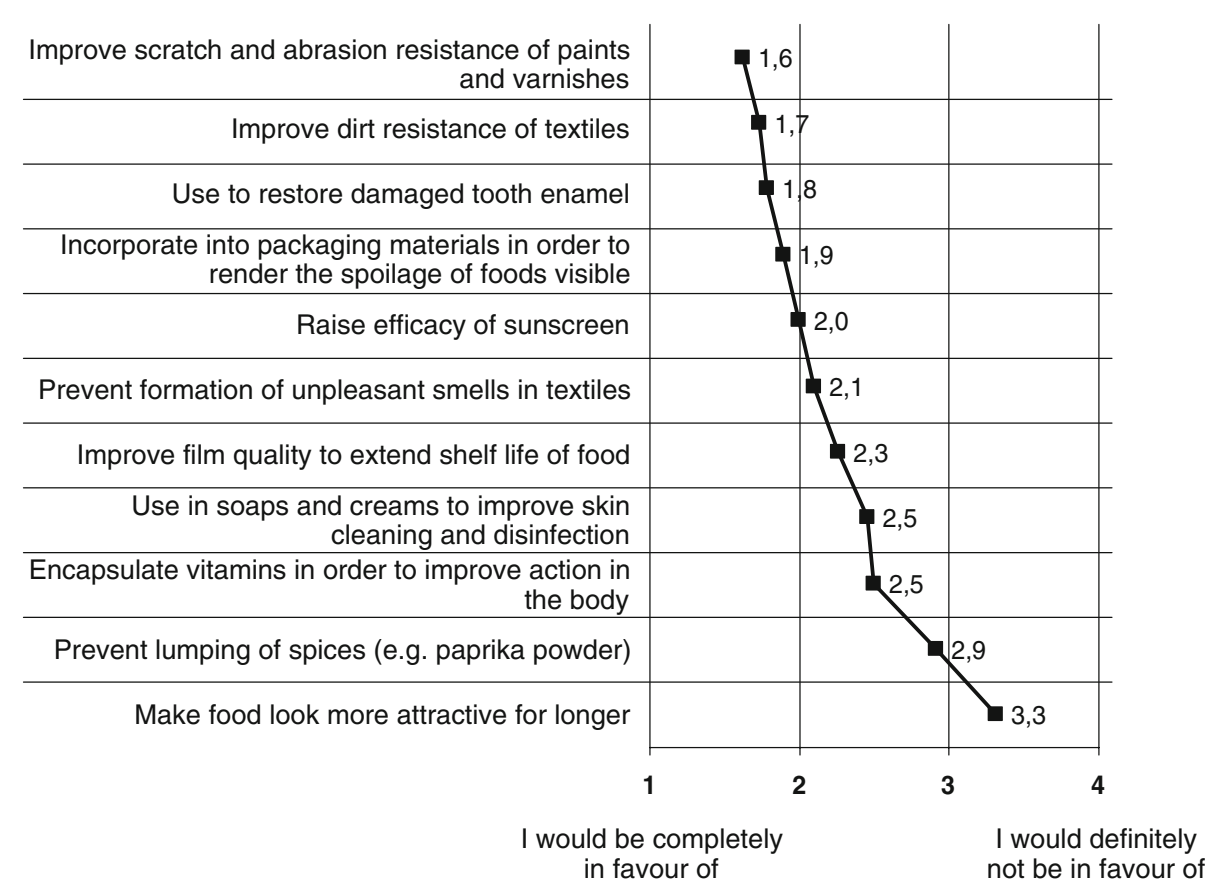

Fig. 3 Acceptance of nanotechnology in different products (average score on a four-point scale)

A consensus conference ${ }^{5}$ on nanotechnology (Zimmer et al. 2007; Zschiesche et al. 2009) produced comparable results.

- Within the medical context, nano particles in sunscreen are regarded as acceptable, as they afford improved UV protection and reduce the risk of skin cancer.

- Improvements of clothes based on nanotechnology were not regarded as risky.

- Improving food characteristics (flowability of ketchup or spices) with the help of nanotechnology was not regarded as important enough to balance or outweigh potential risks.

Non-specified concerns in the area of food are highlighted in other studies as well [see TA-Swiss (2006) and Fleischer and Quendt (2007)].

A look at the results of the Australian survey (MARS 2008) reveals a similar structure (Fig. 4).

\footnotetext{
5 The consensus conference methodology was developed and is used in Denmark. The subject matter and goal of this consumer participation procedure is to assess new technologies and scientific developments from the angle of informed lay persons (citizens or consumers).
}

The 2007 survey in the United States reveals deep scepticism about using nanotechnology in the area of food as well. Only $12 \%$ would use food storage containers and just $7 \%$ would purchase food enhanced with nanotechnology. The majority states that it needs to have more information about health risks and benefits $(73 \%$ and $62 \%)$. Thirteen percent would not use food containers and $29 \%$ would not purchase food enhanced with nanotechnology.

Siegrist et al. (2007) analysed the risk perception of nanotechnology with the help of the psychometric paradigm and placed the hazards perceived by lay persons in a two-component space with the axes Dread Risk and Distrust. Looking at the position of different applications on the dread-risk axis, there is some additional evidence for the above-mentioned factors that drive risk perception. Scores of the factor dread risk are high for sunscreen, food packaging, ammunition, water sterilisation and nano-technological transport capsules that make it possible to release medication specifically in the targeted organ and biosensors to control the food's level of freshness. The scores are low for improving data memory, the treatment of skis, preserving colours on photographic paper, storage of hydrogen as a gasoline substitute and improving the performance of car paints or car tyres. 


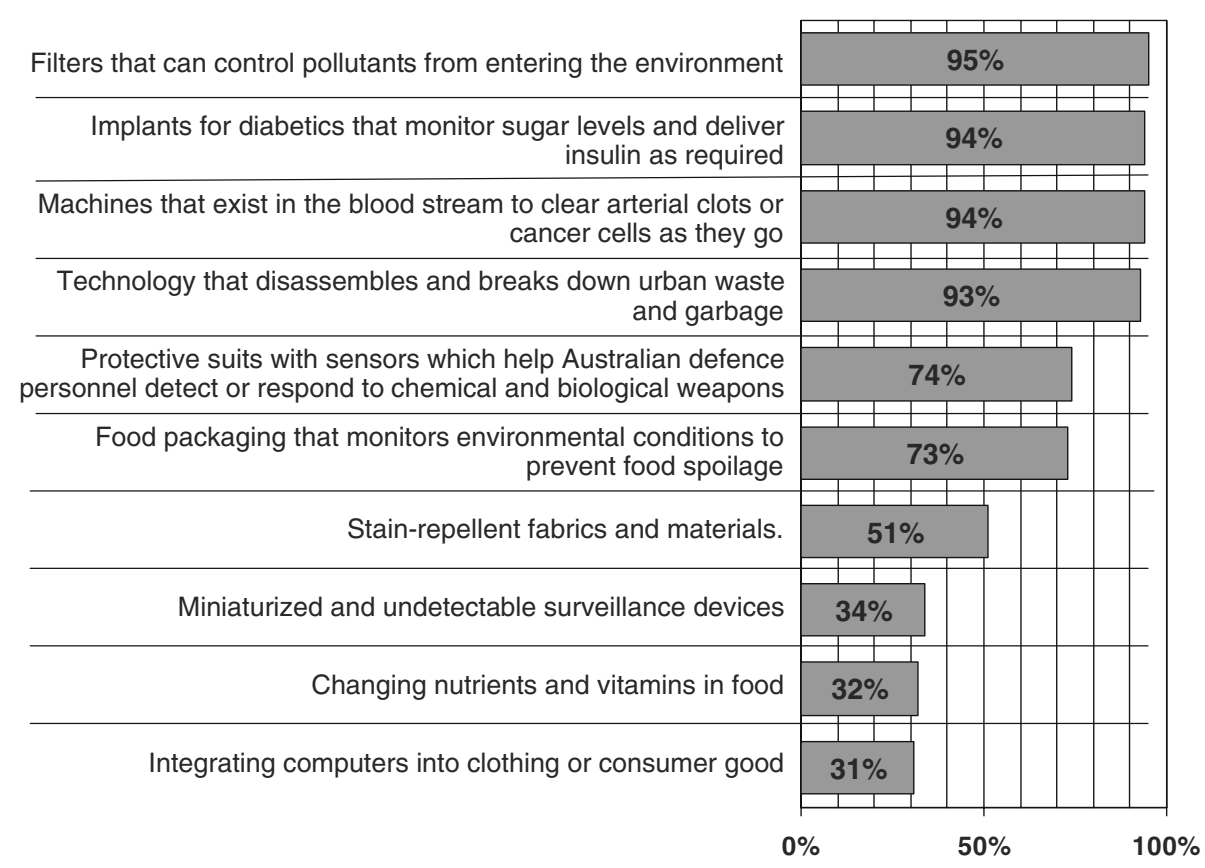

Fig. 4 Acceptance of nanotechnology in different products in Australia (average score on a four-point scale) (MARS 2008)

These results are of special relevance as the respondents were explicitly adverted to the risk that nano particles may disperse in the environment, that they may enter the human body via different pathways, and that the impact is largely unknown. The description of the risk by the interviewer triggered fears that people do not spontaneously have. This approach does highlight the relevance of the distance between the human body and the product for assessing dread risk.

Trust in the institutions providing information

In an environment of information overload and gaps in knowledge about nanotechnology, people are faced with the challenge of assessing whether the risks are serious and real (Härlen et al. 2004). People know from other fields of discussion that information on the relevance of risks differs considerably between different stakeholders and that even science does not speak with one voice (Slovic 1993; Renn 1995).

If people wish to decide whether to take part in the public debate or vary their purchasing behaviour, then they face the problem of dealing with imperfect, contradictory information. Therefore, trust in the institution providing the information plays a key role in the perceived credibility of that information (Flynn et al. 1992; Siegrist 2000, Renn and Levine 1991).
For consumers and citizens, it is highly relevant who provides the information. Target-oriented communication should take this into account.

Based on the above, we asked consumers about their trust in different institutions with respect to information about nanotechnology. The results are summarised in Fig. 5. Obviously, trust is driven especially by (1) a perceived identity of interests between consumers and the institution providing the information and (2) by competence. In the BfR survey, the vast majority of respondents trust, at least to a little extent, consumer organisations and scientists. Trust in medical doctors, environmental organisations as well as the authorities responsible for health and occupational safety is on a lower but nonetheless very high level, too. In contrast, they have very little trust in corporate and government representatives (Vierboom et al. 2009).

These results are backed by several other studies on nanotechnology worldwide (Elkins 2005; Fujita and Abe 2005; HRA 2006, 2007). According to a study by Cobb and Macoubrie (2004), more than $60 \%$ of the respondents said they had not much trust in business leaders' ability or willingness to minimise risks to humans. In the Komm.Passion study (2004), half of the respondents agreed with the statement The risk is great that economic enterprises will use the 


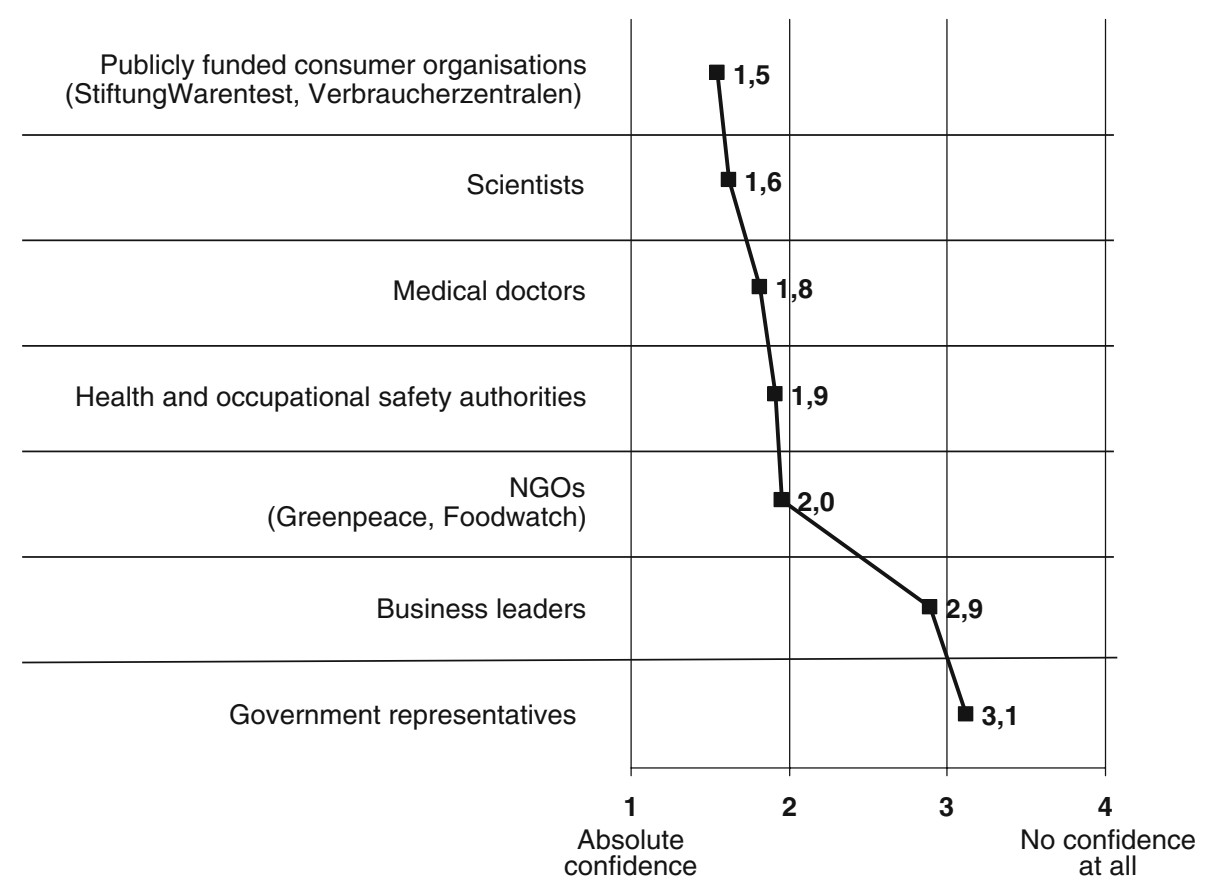

Fig. 5 Confidence in information about nanotechnology depending on the institution involved (average score on a four-point scale)

nanotechnology irresponsibly. In Australia (MARS 2008), scientists were rated as the most trustworthy actors in the field of nanotechnology (88\% of the population rated a lot of trust or some trust in scientists as the source for providing information on risk), followed by non-government organisations (64\%) and government agency regulators (61\%). And a quarter of the Australian population has no trust at all when business leaders or manufacturers of consumer products are the source of risk information.

\section{Summary and conclusions for risk communication}

In Germany, many people see nanotechnology as a means to solving the urgent problems facing humanity, particularly in the context of medicine and the environment. This attitude is driven by hopes and expectations rather than by knowledge. Nevertheless, the majority feels good or very good about the technology and risk perception is very vague because people do not spontaneously come up with terrifying pictures or stories. In summary, the overall risk perception of nanotechnology in Germany can be characterised as follows:
- Nanotechnology raises expectations and hopes for improvements, especially in the fields of medicine and environment. Hope and fascination, coupled with a lack of knowledge, do not leave much room for perceiving risks.

- In addition, people realise that miniaturising and self-cleaning effects are part of their everyday lives. Hence, they feel more familiar with the technology that provides benefits. In particular, the idea that nanotechnology copies nature, as well as the miniaturising products, tends to allay fears.

- Risk perception is mainly driven by vague fears. A considerable part of the population is aware that there might be a risk but there are no emotionally stirring stories or pictures to help concretise that risk. That is why risk perception is scarcely anchored at all in emotions.

- With respect to controllability, nanotechnology is seen differently from other technologies. It is deemed to be tangible and a material dissimilar to the material used in radiation or radioactivity connected to nuclear power. It is viewed differently from genetic engineering because it does not interfere in genetic material. The negative context 
of the other technologies is not at all conferred on nanotechnology.

- Risk perception depends on whether nano particles are integrated and bound in grids or not. Particles that are not bound in grids are perceived as highly threatening. People believe that these particles are uncontrollable and imbued with a destructive power. In contrast, ordered structures of nano particles seem to be controllable and calming.

- The appraisal of nanotechnology is more differentiated when it comes to the acceptance of its use in producing and designing different (groups of) products. When it comes to food, in particular, the overwhelming majority of the population is against nanotechnology. Therefore, it is obvious that nanotechnology and food makes the majority feel at least uncomfortable and that it does not enjoy acceptance.

In the case of Germany, we found that nanotechnology can be used to counterbalance adverse attitudes towards technological developments. In this way, it helps people to once again believe in the benefits of technological progress and to look more optimistically to the future. Additional qualitative research may show whether these results are specific for Germany or whether they apply in general to developed nations.

Comparison of the results from standardised questionnaires in Germany with those from Australia and the United States reveal similar structures. Although the in-depth interviews were conducted with people living in Germany, the consistency of the quantitative results lends some empirical weight to the hypothesis that these basic findings may hold for Australia and the United States, too. However, additional research is necessary to further substantiate this hypothesis.

Though risk awareness is low, fears can easily be triggered by news linking nanotechnology to concrete hazards or media reports of human suffering and harm. The lack of knowledge makes it very difficult for people to undertake a differentiated risk appraisal.

As risk assessment of nanotechnology is in its infancy, information on risks may emerge and oblige responsible institutions to react. Lack of knowledge, as well as different and inconsistent conditions that help people to evaluate nanotechnology make it difficult to estimate the effects of risk communication. When they have little knowledge about how nanotechnology works, it is difficult for people to comprehend whether communicated risks refer to nanotechnology in general or only to some products or specific branches of nanotechnology.

Given that people know or have experienced benefits of what they perceive to be nanotechnology, risk communication may lead to reactance. People do not believe in information and find several ways of ignoring it or qualifying it. Against the backdrop of information overload and ambiguous risk information, it is easy to find reasons for classifying information as irrelevant. In this case, it is difficult to warn the public.

On the other hand, risk information referring to a special application may be taken as a hint of an overall risk of nanotechnology and, by extension, of a positive attitude towards the new technology. Parallels to the risk perception of genetic engineering provide evidence that the acceptance of the use of nanotechnology in medicine will not fundamentally change. However, acceptance and risk perception in the context of environmental technology and consumer products may be considerably affected by such information. In this case, it is difficult to placate the public.

Hence, for targeted risk communication. it is important to develop strategies that help people to comprehend nanotechnology, to differentiate between the fields of application and to gain an understanding of the cause and effect chains. This approach prevents people from feeling powerless and being at the mercy of a technology which they can neither control nor understand. Providing information is not enough. Information must be offered in such a way that it helps interested people to be informed about nanotechnology in spite of their limited knowledge about engineering and natural sciences.

Even if people gain more insight into the concept of nanotechnology and its different fields, the problem of information overload and ambiguous information remains. Therefore, it is important to involve trusted institutions in the risk communication process. This could help people to accept the information because they do not suspect the communicator of having some hidden interests or of deceiving them with misleading information.

Strategies for communicating about nanotechnology should be in place before any negative news makes the headlines, which can be easily associated 
with nanotechnology. Given that it takes time and extensive research to develop and disseminate strategies of this kind to relevant institutions, work should begin immediately.

Acknowledgement The authors gratefully acknowledge the anonymous review and the comments that helped in improving this article.

\section{References}

Alhakami AS, Slovic P (1994) A psychological study of the inverse relationship between perceived risk and perceived benefit. Risk Anal 14:1085-1096. doi:10.1111/j.15396924.1994.tb00080.x

Cobb MD, Macoubrie J (2004) Public perceptions about nanotechnology: risks, benefits and trust. J Nanopart Res 6:395-405. doi:10.1007/s11051-004-3394-4

Damasio AR (1994) Decartes' error: emotion reason and the human brain. Grosset/Putnam, New York

Elkins N (2005) Nanotechnology: a national survey of consumers. Report prepared for Dandolo Partners

Fitzek H, Salber W (1996) Gestaltpsychologie: Geschichte und Praxis. Darmstadt

Fleischer T, Quendt C (2007) „Unsichtbar und unendlich” Bürgerperspektiven auf Nanopartikel Ergebnisse zweier Fokusgruppen-Veranstaltungen in Karlsruhe. Wissenschaftliche Berichte FZKA 7337

Flynn J, Burns W, Mertz CK, Slovic P (1992) Trust as a determinant of opposition to a high-level radioactive waste repository: analysis of a structural model. Risk Anal 12:417-429. doi:10.1111/j.1539-6924.1992.tb00694.x

Fujita Y, Abe S (2005) Questionnaire survey report on nanotechnology and society. Report des Nanotechnology Research Institute

Gaskell G, Allansdottir A, Allum N, Corchero C, Fischler C, Hampel J, Jackson J, Kronberger N, Mejlgaard N, Revuelta G, Schreiner C, Stares S, Torgersen H, Wagner W (2006) Europeans and biotechnology in 2005: patterns and trends. Eurobarometer 64.3. A report to the European Commission's Directorate-General for Research

Härlen I, Simons J, Vierboom C (2004) Die Informationsflut bewältigen - Über den Umgang mit Informationen zu Lebensmitteln aus psychologischer Sicht (How to cope with information overload-a psychological view on processing information about food). Dr. Rainer Wild Stiftung, Heidelberg

Henddickx L, Vlek C, Oppewal H (1989) Relative importance of scenario and information and frequency information in the judgement of risk. Acta Psychol (Amst) 72:41-63. doi: 10.1016/0001-6918(89)90050-4

HRA-Hart Research Associates, Inc. (2006) Report findings. Conducted on behalf of: Project on Emerging Nanotechnologies, The Woodrow Wilson International Center for Scholars. www.nanotechproject.org/file_download/98. Accessed 21 April 2009

HRA-Hart Research Associates, Inc. (2007) Awareness of and attitudes toward nanotechnology and federal regulatory agencies. A report of findings conducted on behalf of: Project on Emerging Nanotechnologies, The Woodrow Wilson International Center for Scholars. http:// www.pewtrusts.org/uploadedFiles/wwwpewtrustsorg/Reports/ Nanotechnologies/Hart_NanoPoll_2007.pdf. Assessed 21 April 2009

HRA - Hart Research Associates, Inc. (2008) Awareness of and attitudes toward nanotechnology and synthetic biology. A report of findings conducted on behalf of: Project on Emerging Nanotechnologies, The Woodrow Wilson International Center for Scholars. http://www.nanotechproject. org/process/assets/files/7040/final-synbioreport.pdf. Accessed 21 April 2009

Kahan DM, Slovic P, Braman D, Gastil J, Cohen G (2007) Nanotechnology risk perceptions: the influence of affect and values. Conducted by the Cultural Cognition Project at Yale Law School. http://www.nanotechproject.org/process/assets/ files/2710/164_nanotechriskperceptions_dankahan.pdf. Accessed 21 April 2009

Komm.Passion GmbH (2004) Wissen und Einstellungen zur Nanotechnologie. http://www.komm-passion.de/fileadmin/ bilder/themen/pdf/Nanostudie_kurz.pdf. Accessed 21 April 2009

MARS-Market Attitude Research Service (2005) Australian community opinion towards nanotechnology and the commercialisation of scientific research. Short report. http://www. innovation.gov.au/Industry/Nanotechnology/Documents/ $2004 \% 20$ MARS $\% 20$ Community $\% 20$ Survey $\% 20$ Nov\% 2004.pdf. Accessed 21 April 2009

MARS-Market Attitude Research Service (2007) Australian community attitudes held about nanotechnology - trends 2005 to 2007. Final report. http://www.innovation.gov.au/ Industry/Nanotechnology/Documents/MARSreport200708 01094555.pdf. Accessed 21 April 2009

MARS-Market Attitude Research Service (2008) Australian community attitudes held about nanotechnology - trends 2005 to 2008. Presentation report. http://www.innovation. gov.au/Industry/Nanotechnology/Documents/Summary_ Report_Public_Attitudes_towards_Nanotechnology_2008. pdf. Accessed 21 April 2009

Renn O (1995) Style of using scientific expertise: a comparative framework. Sci Public Policy 22:147-156

Renn O, Levine D (1991) Trust and credibility in risk communication. In: Kasperson R, Stallen PJ (eds) Communicating risk to the public. Kluwer Academic Publishers, Dordrecht, pp 175-218

Rosenbladt B, Schwupp J (2007) Nanotechnologie in der Bevölkerung noch wenig bekannt. In: Deutsches Institut für Wirtschaftsförderung (ed) Wochenbericht, $74 \mathrm{Jg} \mathrm{Nr}$. 45/2007, pp 673-677. http://www.diw.de/documents/ publikationen/73/74781/07-45-1.pdf. Accessed 21 April 2009

Schulte K (2005) Lernen durch Einsicht. Erweiterung des gestaltpsychologischen Lernbegriffs. VS Verlag für Sozialwissenschaften, Wiesbaden

Schütz H, Wiedemann PM (2008) Framing effects on risk perception of nanotechnology. Public Underst Sci 17:369379

Siegrist M (2000) The influence of trust and perception of risks and benefits on the acceptance of gene technology. Risk Anal 20:195-203. doi:10.1111/0272-4332.202020 
Siegrist M, Keller C, Kastenholz H, Frey S, Wiek A (2007) Laypeople's and experts' perception of nanotechnology hazards. Risk Anal 27:59-69. doi:10.1111/j.1539-6924. 2006.00859.x

Slovic P (1993) Perceived risk, trust, and democracy. Risk Anal 13:675-682. doi:10.1111/j.1539-6924.1993.tb01329.x

Slovic P, Fischhoff B, Lichtenstein S (2000) Facts and fears: understanding perceived risk. In: Slovic P (ed) The perception of risk. Earthscan Publications, London, pp 137-153

TA-Swiss (2006) Nanotechnologien in der Schweiz: Herausforderungen erkannt. Bericht zum Dialogverfahren publifocus „Nanotechnologien und ihre Bedeutung für Gesundheit und Umwelt". Zentrum für Technologiefolgen-Abschätzung TA-P 8/2006 d

Vierboom C, Härlen I, Simons J (2009) Public perceptions about nanotechnology. Representative survey and basic morphological-psychological study. In: Zimmer R, Hertel R, Böl GF (eds) Wissenschaft 01/2009. http://www.bfr. bund.de/cm/290/public_perceptions_about_nanotechnology. pdf. Accessed 21 April 2009

Wiedemann PM, Schütz H (2001) Risiko-Stories und Risikobewertung. Paper des Forschungszentrums Jülich, Programmgruppe Mensch, Umwelt, Technik

Zimmer R, Domasch S, Scholl G, Zschiesche M, Petschow U, Hertel RF, Böl GF (2007) Nanotechnologien im öffentlichen Diskurs: Deutsche Verbraucherkonferenz mit Votum. Technikfolgenabschätzung - Theorie und Praxis 3:98-101. http://www.itas.fzk.de/tatup/073/ziua07a.pdf. Accessed 21 April 2009

Zschiesche M, Domasch S, Petschow U, Scholl G, Renn O, Ulmer F (2009) BfR consumer conference nanotechnology. Pilot project to identify consumer risk perception. In: Zimmer R, Hertel R, Böl GF (eds) BfR Wissenschaft 03/2009. http://www.bfr.bund.de/cm/238/bfr_ consumer_conference_nanotechnology.pdf. Accessed 21 April 2009 